\title{
Renal effects of vasodilators in acute heart failure
}

\author{
Mattia A. E. Valente, Adriaan A. Voors \\ Department of Cardiology, University Medical Center Groningen, Groningen, The Netherlands \\ Email: a.a.voors@umcg.nl
}

Received 15 January 2013; revised 18 March 2013; accepted 16 April 2013

Copyright ( 2013 Mattia A. E. Valente, Adriaan A. Voors. This is an open access article distributed under the Creative Commons Attribution License, which permits unrestricted use, distribution, and reproduction in any medium, provided the original work is properly cited.

\begin{abstract}
Vasodilator therapy is common in acute heart failure (AHF) patients, although evidence for morbidity and mortality benefits is limited for many of these drugs. AHF is frequently accompanied by renal dysfunction, which is a strong, independent predictor for poor prognosis. Several hemodynamic and neurohormonal effects of vasodilators-including preload and afterload reduction, activation or inhibition of neurohormonal and inflammatory cascades-have the potential to modulate cardiorenal interaction and impact renal function. However, the effect of vasodilators on renal function in acute heart failure is often poorly described. In this review, we provide an overview of the known cardiorenal effects of traditional and novel vasodilators in patients with acute heart failure.
\end{abstract}

Keywords: Heart Failure; Vasodilators; Cardiorenal Syndrome; Renal Function

\section{INTRODUCTION}

Acute heart failure (AHF) is a heterogeneous collection of syndromes with variable aetiologies and clinical profiles. Despite this, initial management is relatively uniform-albeit with regional variation —and focused on hemodynamic stabilization and symptom control. Diuretics for decongestion, supportive therapy with oxygen, and treatment with opiates, vasodilators and inotropics in selected patients are the foundation of AHF management - a paradigm that has not changed significantly in decades. The evidence for survival benefits of many vasodilators in acute heart failure is limited. According to the 2012 European Society of Cardiology heart failure guidelines, vasodilators "may" or "should" be considered in AHF patients presenting with normal or elevated blood pressure in the absence of valvular disease (class IIa and IIb recommendations, level of evidence B or C) [1].
Chronic kidney disease is common in AHF, with reported rates of up to 30\% in registry studies [2] and 37\% in randomised trials [3]. Renal function is a strong, independent predictor for outcome in AHF, including increased risk of death and higher rehospitalization rates [4]. In addition to renal impairment caused by AHF directly, therapies such as diuretics and vasodilators may affect renal function. The effects of vasodilators on renal function are important, but unfortunately often remain unexamined. This review will focus on what is known about the renal effects of vasodilator treatment in AHF.

\section{DEFINING RENAL FUNCTION}

Creatinine has a long history as a marker for renal function. Serum creatinine and glomerular filtration rate (GFR) estimated using creatinine-based formulas-CockroftGault, Modification of Diet in Renal Disease (MDRD) and more recently, Chronic Kidney Disease Epidemiology Collaboration (CKD-EPI) formulas-are the measures most commonly used in both research and clinical settings to monitor renal function, and are strongly correlated with each other and with clinical outcome $[5,6]$. In recent years, interest in and evidence for the prognostic value of other markers for renal function has grownincluding cystatin C, Blood Urea Nitrogen (BUN) and a host of novel serum and urinary markers [7-10]. Although a number of these novel markers outperform creatininebased equations for risk stratification and provide insight into aspects of renal function other than GFR-particularly tubular function - the majority of the literature is based on creatinine-derived measures for renal function $[7,11,12]$.

\section{CARDIORENAL INTERACTION AND VASODILATORS}

Cardiorenal interaction in acute heart failure-collectively referred to as type 1 cardiorenal syndrome-is common, occurring in over $30 \%$ of hospitalized patients 
$[13,14]$. Although poor renal function is consistently associated with poor prognosis, the data on worsening renal function during hospitalization for AHF are mixed [4, 15-17]. There are indications that transient worsening of renal function may even be beneficial [16]. Such transient changes may reflect good treatment response rather than lasting injury.

The mechanisms responsible for the high prevalence of renal dysfunction in heart failure populations are complex [18]. Chronic comorbid conditions endemic in heart failure populations, such as hypertension, diabetes mellitus and atherosclerosis, result in chronic kidney disease. The direct hemodynamic consequences of AHF play key roles in acute injury, and can ultimately lead to lasting renal damage: forward failure and backward failure. A reduction in cardiac output (forward failure) triggers renal vasoconstriction and a drop in renal blood flow. Compensatory angiotensin II release and efferent arteriolar vasoconstriction increase the filtration fraction (GFR to renal blood flow ratio), preserving GFR for a relatively long time $[19,20]$. In patients on renin-angiotensin-aldosterone system (RAAS) blockers-guideline therapy for heart failure-the kidney's ability to increase the filtration fraction is blunted, making the kidney critically de- pendent on renal blood flow to maintain GFR [21]. The rise in venous pressures in AHF (backward failure) reduces venous compliance, while congestion and rising intra-abdominal pressures contribute to a further drop in renal blood flow [20,22].

Beyond the response to hemodynamic changes, the complex network of pathophysiological processes present in heart failure-including myocardial injury, inflammation, response to fluid retention, arrhythmias, RAAS and sympathetic nervous system activation - can exacerbate renal impairment (Figure 1) [13]. Regional vasoconstriction can limit renal blood flow independently of blood pressure, leading to impaired renal function even if cardiac output is preserved [21]. Various other neurohormonal processes, including endothelial activation and adenosine release can cause tubular injury and nephron loss. Persistent low flow states, neurohormonal activation and inflammation can ultimately lead to nephrosclerosis and fibrosis, with permanent renal injury and dysfunction as a result [23]. Diuretic treatment also leads to decreased renal blood flow and glomerular filtration via tubuloglomerular feedback. This mechanism is regulated by adenosine-mediated vasoconstriction and results in compensatory tubular sodium retention [24].

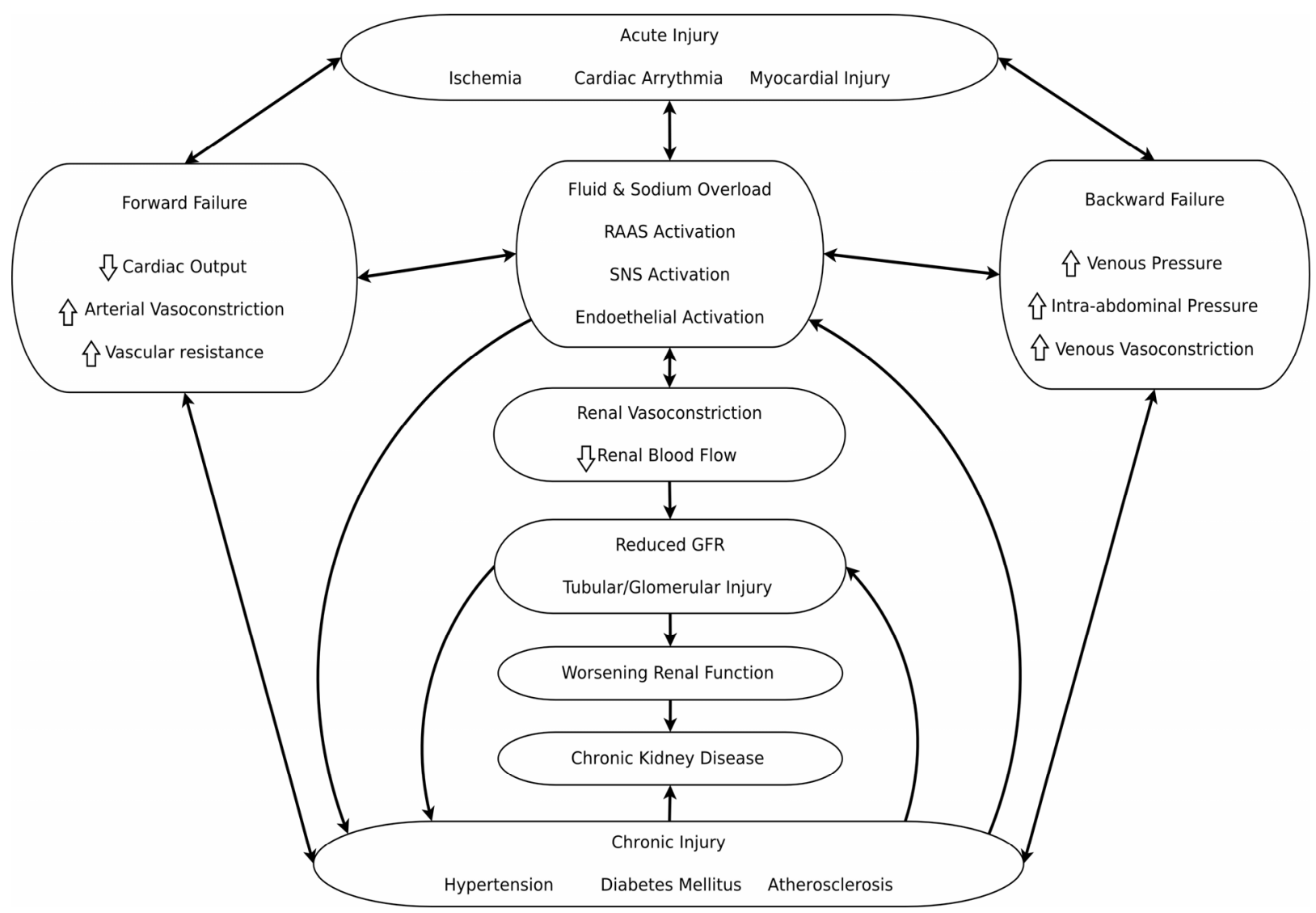

Figure 1. Mechanisms of renal dysfunction in heart failure. RAAS: renin-angiotensin-aldosterone system; SNS: sympathetic nervous system. 


\section{Renal Effects of Vasodilators in AHF}

Given the key role vascular tone plays in preserving renal function, vasodilating therapies that improve or protect renal perfusion may be of value in AHF. Vasodilators are a double-edged sword where renal function is concerned-while counteracting regional vasoconstriction may improve renal perfusion, the potential drop in blood pressure may have negative effects. The balance between these effects will depend on the individual patient's hemodynamic profile, congestive state and the specific pharmacological properties of individual vasodilators. Careful selection and (hemodynamic) monitoring of patients is required in order to achieve the positive effects-preload and afterload reduction-without the negative-decreased perfusion due to a drop in blood pressure, shock and rebound neurohormonal activation.

\section{RENAL EFFECTS OF SPECIFIC VASODILATORS}

\subsection{Nitrates}

Nitrates-nitroprusside and nitroglycerine--have a long history in the management of AHF. Nitroglycerine is a potent venodilator with mild arterial vasodilating effects. Its primary effects are achieved by decreasing venous preload, alleviating filling pressures, wall stress and thus myocardial oxygen consumption, as well as reducing systemic vascular resistance. Cardiac output generally remains stable or rises [25]. Small studies have shown some effects on symptom relief and short-term outcome, but solid evidence for survival benefit is lacking [26,27]. Effects on renal function have not been studied.

Nitroprusside is a balanced venous and arterial vasodilator that acts on smooth muscle cells, reducing preload and afterload. One small, observational study found an association between nitroprusside therapy and improved renal and hemodynamic outcomes, despite worse hemodynamic profiles at baseline [28]. Both nitroglycerine and nitroprusside therapy have been associated with rebound neurohormonal activation, which may negate some of the potentially beneficial effects of vasodilation on renal blood flow.

\subsection{Milrinone}

Milrinone is a selective phosphodiesterase- 3 inhibitor which improves cardiac contractility by preventing degradation of cyclic AMP in cardiomyocytes. Though often used for its positive inotropic effects, it also has peripheral vasodilating properties that contribute to afterload reduction. Although short-term hemodynamic improvement has been described for milrinone, long-term oral use has been associated with increased mortality [29,30]. Common side-effects include — as with all vasodilators- hypotension. It should be used with caution in patients with pre-existing renal dysfunction, as it is cleared primarily via the glomerulus [31].

Results from the Outcomes of a Prospective Trial of Intravenous Milrinone for Exacerbations of Chronic Heart Failure (OPTIME-CHF) trial showed slight improvement in renal function with Milrinone treatment, without any mortality impact [32]. However, renal function was not a predefined outcome parameter. Based on its mechanism of action, Milrinone has to potential to help preserve renal function as long as adequate renal blood flow is maintained.

\subsection{Endothelin Antagonists}

Endothelin-1 (ET-1) is a powerful vasoconstrictor with a variety of pro-inflammatory, mitogenic and pro-fibrotic properties, and is a potential treatment target in AHF. Elevated levels have been observed in AHF patients, and are associated with increased morbidity and mortality, which led to the development and study of various endothelin antagonists, including Tezosentan, Darusentan, Sitaxsentan and Bosentan [33,34]. Tezosentan has been studied most extensively in AHF. Treatment results in lower pulmonary wedge pressure and higher cardiac index. Despite a safe clinical profile in high-risk AHF patients, multiple large-scale studies with Tezosentan failed to show clinical benefit, with some terminated early due to lack of effect [3,35-37].

ET-1 plays a key role in the kidney, modulating renal blood flow, GFR, sodium exchange and acid-base balance. Receptors are present throughout various kidney compartments. In addition to regulating blood pressure via vasoconstriction, ET-1 both directly and indirectly regulates sodium and water retention, with elevated levels triggering natriuresis and diuresis in the healthy kidney [34]. In kidney disease, ET-1 has been associated with increased inflammatory and fibrotic response, playing a key role in proteinuria-mediated injury and in nephron loss [38]. Blockade of ET-1 receptors in the kidney may counteract vasoconstriction and inhibit inflammation and remodeling cascades. In heart failure, renal ET-1 levels rise before plasma levels, and correlate with worse New York Heart Association (NYHA) functional class and outcome [34]. Although there is evidence from animal models that ET-1 blockade can prevent renal injury and the theoretical pathophysiological framework for use of ET-1 antagonists to preserve renal function appears sound, evidence from human trials in AHF is extremely limited and inconclusive.

\subsection{Guanylate Cyclase System Activators- Natriuretic Peptides}

Recombinant natriuretic peptides have been investigated 
for the treatment of acute heart failure, with early studies showing favourable hemodynamic effects [39-42]. These substances, released in response to myocardial stretch (B-type), atrial stretch (A-type) and by the vascular endothelium (C-type), activiate the particulate guanylate cyclase system and initiate a cascade resulting in increased diuresis, vasodilation and lower blood pressure [43].

Nesiritide is a recombinant form of B-type Natriuretic Peptide with vasodilator and natriuretic properties, authorized for AHF treatment in the USA but not Europe. Although there is evidence for effective symptom relief, some studies reported higher re-admission and mortality rates as well as more renal damage [39,40,44-46]. The prospective Acute Study of Clinical Effectiveness of Nesiritide in Decompensated Heart Failure (ASCENDHF) trial, however, found no survival benefit for nesiritide treatment in a population of over 7000 patients with severe acute heart failure, nor was a higher incidence of worsening renal function observed [47]. Although nesiritide treatment appears to be safe, benefits in terms of outcome and renal function are not apparent.

Other novel investigational natriuretic peptides include ularitide and CD-NP. Ularitide is a recombinant form of A-type natriuretic peptide that acts on the renal tubule and plays a role in sodium and water excretion, with early hemodynamic studies reporting improved symptoms, hemodynamics and diuresis [41,48]. One small study in AHF patients found ularitide preserves shortterm renal function, possibly by maintaining cardiac output and preserving the pressure gradient between mean arterial and renal arterial pressures [49]. Data on longterm renal outcomes are not available.

CD-NP is a fusion product of C-type and D-type natriuretic peptides, with natriuresis promoting, GFR enhancing, renin inhibiting and decongestive effects, with a lower risk of hypotension and greater preservation of GFR compared with B-type peptides [42,50,51]. Current data are limited to animal studies, with human trials still underway [52].

Natriuretic peptides are released by various tissues in response to volume overload, and their natriuretic and vasodilator effects may improve renal perfusion and increase water and salt excretion. The current evidence in AHF does not suggest any specific benefit, though data on ularitide and CD-NP appear promising.

\subsection{Guanylate Cyclase System Activators-BAY 58-2667/Cinaciguat}

Natriuretic peptides exert their effect by activating particulate guanylate cyclase in various tissues. An analogous enzyme, soluble guanylate cyclase (sGC), is present in the vascular endothelium and activated by nitric oxide
(NO). The endothelial dysfunction common in heart failure can result in impaired NO formation and responsiveness [53], which led to the development of novel methods for sGC system activation.

BAY 58-2667, or Cinaciguat, is a potent, NO-independent sGC activator [54]. Administration to HF patients in a dose-finding study and a phase IIb study showed significant reduction of filling pressures, blood pressure and both systemic and pulmonary vascular resistance, accompanied by elevated heart rate, cardiac output and improvement in dyspnea [55,56]. Infusion increases norepinephrin and plasma renin activity, and symptomatic hypotension is common [56]. Results from a series of phase IIb studies in AHF patients showed similar results, but the studies were terminated early due to excess hypotension in the cinaciguat arms [57]. The early termination of these studies makes it unlikely this drug has a future in the treatment of AHF, and though its renal effects are unknown, the potential for harm due to hypoperfusion and RAAS activation would seem to outweigh the theoretical unloading benefits for the kidney.

\subsection{Vasopressin Antagonists}

Arginine vasopressin is a hormone released by the pituitary gland with antidiuretic and vasoconstrictor effects. Low blood pressure present in HF triggers its release, and stimulation of V1 and V2 receptors causes, among other effects, vasoconstriction and changes in the renal collecting tubules, leading to reduced diuresis and hyponatermia. Antagonism of vasopressin receptors in AHF aims to increase water clearance while retaining sodium and preventing RAAS activation [58].

Tolvaptan is a selective oral V2 receptor antagonist that showed promise in phase II trials in HF patients, improving hyponatremia, increasing weight loss and reducing oedema without significant adverse effects [5961]. The Efficacy of Vasopressin Antagonism in Heart Failure Outcome Study with Tolvaptan (EVEREST) trial confirmed some of these positive results, showing improved dyspnea relief without negative effects on longterm mortality or HF morbidity [62,63]. Available data does not show any negative effects on renal function.

Conivaptan is an intravenous non-selective vasopressin antagonist. Despite non-selective vasodilating properties, early results suggest its safety and efficacy are similar to that of tolvaptan $[64,65]$. There are indications that conivaptan may have a more beneficial cardiorenal profile, with data from animal studies showing a reduction in afterload, compared with an increase for tolvaptan [66]. One small-scale study in chronic heart failure patients found a significant improvement in diuresis and natriuresis following conivaptan administration, without negative effects on glomerular filtration rate, renal blood 
flow or neurohormonal activation [67]. Overall, there is no suggestion that vasopressin antagonists negatively affect renal function, and there are indications of positive effects.

\subsection{Adenosine A-1 Receptor Antagonists}

Elevated adenosine levels, commonly present in patients with AHF, can cause afferent arterial vasoconstriction resulting in decreased renal blood flow and, ultimately, renal damage. Adenosine A-1 receptor antagonists prevent reduction of renal blood flow and GFR caused by adenosine release triggered by tubuloglomerular response to sodium overload in the distal tubule [24].

Rolofylline, an intravenous selective A-1 receptor antagonist, has been studied in heart failure patients. Early results showed that administration of rolofylline significantly increases renal blood flow and glomerular filtration $[68,69]$. However, the prospective PROTECT (Placebo-Controlled Randomized Study of the Selective A-1 Adenosine Receptor Antagonist Rolofylline for Patients Hospitalized with Acute Decompensated Heart Failure and Volume Overload to Assess Treatment Effect on Congestion and Renal Function) study found no significant impact of rolofylline administration on outcome, renal function or dyspnea relief $[16,70]$. Tonapofylline, an oral and intravenous A-1 receptor antagonist, showed similar promise in early trials, with positive effects on diuresis while preserving GFR [71,72]. However, the results of the unpublished and prematurely terminated Treatment with intravenous BG9928 for Patients with Acutely Decompensated Heart Failure and Renal Insufficiency (TRIDENT-1) trial showed results consistent with those of PROTECT — no impact on outcome, weight loss or renal function.

\subsection{Levosimendan}

Levosimendan is a phosphodiesterase inhibitor that improves cardiomyocyte contractility by increasing calcium sensitivity, improving both systolic and diastolic function [73-75]. It also has vasodilator effects achieved by binding to adenosine triphosphate-sensitive potassium channels in vascular smooth muscle [76,77]. These mechanisms result in improved cardiac output with both preload and afterload reduction.

The REVIVE trials showed symptom relief with levosimendan, but incidence of arrhythmias, hypotension and early mortality was also higher [78]. The SURVIVE study failed to reach the primary endpoint of all-cause mortality reduction or any of the secondary endpoints other than reduction of BNP levels [79]. The RUSLAN and LIDO trials, though underpowered for mortality, did show survival benefit for levosimendan treatment [80, 81].
A number of studies have reported positive effects of Levosimendan treatment on renal function [81-84]. The explanation likely lies with levosimendan's vasodilator activity, with stronger venous compared to arterial vasodilation, along with its positive inotropic effects [85]. As elevated central venous pressures and congestion are associated strongly with reduced GFR [21], Levosimendan treatment will benefit highly congested patients with AHF, as long as cardiac output and blood pressure provide adequate renal perfusion. The balance for patients with low blood pressure may remain neutral or even turn negative.

\subsection{Serelaxin}

Relaxin is an endogenous hormone that regulates maternal adaptations to pregnancy, with numerous potentially interesting effects for the treatment of heart failure [86]. Serelaxin is a recombinant form of this hormone. Activation of relaxin receptors in the heart, kidney and cardiovascular system leads to increased endothelial activity and increased nitric oxide synthase activity, resulting in greater arterial compliance, increased cardiac output, and higher renal blood flow $[87,88]$. In AHF, the Pre-RELAX-AHF and RELAX-AHF trials showed improvement in dyspnea relief and reduced 180-day mortality, but no effects on readmission rates. Hypotension was equally common in both treatment groups [89]. In terms of renal effects, patients receiving serelaxin showed a lower incidence of events related to renal impairment. Subsequent biomarker analysis showed indications that short-term serelaxin administration in AHF patients may improve organ protection-including renal protectionresulting in better 6 month mortality outcomes [90].

\section{DISCUSSION}

Data on the effects of vasodilators on renal function in AHF are limited. While trials investigating novel drugs increasingly include renal outcomes as primary endpoints, the effects of the most commonly used vasodilators - nitrates — on the kidney are largely unknown. Theoretically, the variable local and systemic effects of vasodilators will determine their impact on renal functionboth preload and afterload reduction may be beneficial, provided compensatory neurohormonal activation and blood pressure drops are kept in check. Maintaining hemodynamic stability while improving local blood flow is key, so careful patient selection, monitoring and treatment titration remains essential.

While numerous vasodilators have been studied in AHF, most have failed to deliver on the promise suggested by preclinical and pilot studies. Nitrates are still in common use, and while effective for symptom relief and acute reduction of filling pressures, data on their renal 
effects is practically non-existent. This evidence gap is most glaring for vasodilators introduced over 10 years ago; identification of renal function as a key prognostic indicator in HF is relatively recent, and understanding of its importance has grown steadily over time. This understanding is exemplified by rolofylline-and the PROTECT hypothesis that improving renal blood flow and function could improve outcome in AHF-despite the neutral results of the PROTECT study [16]. Levosimendan has demonstrated renoprotective effects, albeit with inconclusive survival effects, further supporting the hypothesis that vasodilators can benefit renal function in AHF [84,91].

Serelaxin is, without a doubt, the most interesting novel vasodilator in terms of renal function. In addition to reducing renal events, serelaxin also improved mortality outcomes. This unexpected finding makes it the first therapy for acute heart failure to show survival benefit. Furthermore, it underlines the importance of renal function in AHF. Studies investigating existing or novel treatments for AHF should continue to focus on renal outcomes in addition to the more traditional mortality and hospitalization endpoints. There is also a strong case to be made for considering renal function measures that go beyond traditional creatinine-based assessments, and encompass tubular function as well as glomerular filtration. Novel urine and serum biomarkers may have an important role to play.

\section{REFERENCES}

[1] McMurray, J.J., Adamopoulos, S., Anker, S.D., Auricchio, A., Bohm, M., Dickstein, K., et al. (2010) ESC guidelines for the diagnosis and treatment of acute and chronic heart failure 2012: The task force for the diagnosis and treatment of acute and chronic heart failure 2012 of the European Society of Cardiology. Developed in collaboration with the Heart Failure Association (HFA) of the ESC. European Journal of Heart Failure, 14, 803-869. doi:10.1093/eurjhf/hfs105

[2] Adams Jr., K.F., Fonarow, G.C., Emerman, C.L., LeJemtel, T.H., Costanzo, M.R., Abraham, W.T., et al. (2005) Characteristics and outcomes of patients hospitalized for heart failure in the united states: Rationale, design, and preliminary observations from the first 100,000 cases in the acute decompensated heart failure national registry (ADHERE). American Heart Journal, 149, 209-216. doi:10.1016/j.ahj.2004.08.005

[3] McMurray, J.J., Teerlink, J.R., Cotter, G., Bourge, R.C., Cleland, J.G., Jondeau, G., et al. (2007) Effects of tezosentan on symptoms and clinical outcomes in patients with acute heart failure: The VERITAS randomized controlled trials. Journal of the American Medical Association, 298, 2009-2019. doi:10.1001/jama.298.17.2009

[4] Damman, K., Jaarsma, T., Voors, A.A., Navis, G., Hillege, H.L., van Veldhuisen, D.J., et al. (2009) Both in- and out-hospital worsening of renal function predict outcome in patients with heart failure: Results from the coordinating study evaluating outcome of advising and counseling in heart failure (COACH). European Journal of Heart Failure, 11, 847-854. doi:10.1093/eurjhf/hfp108

[5] Smilde, T.D., van Veldhuisen, D.J., Navis, G., Voors, A.A. and Hillege, H.L. (2006) Drawbacks and prognostic value of formulas estimating renal function in patients with chronic heart failure and systolic dysfunction. Circulation, 114, 1572-1580. doi:10.1161/CIRCULATIONAHA.105.610642

[6] Levey, A.S., Stevens, L.A., Schmid, C.H., Zhang, Y.L., Castro 3rd, A.F., Feldman, H.I., et al. (2009) A new equation to estimate glomerular filtration rate. Annals of Internal Medicine, 150, 604-612. doi:10.7326/0003-4819-150-9-200905050-00006

[7] Lassus, J., Harjola, V.P., Sund, R., Siirila-Waris, K., Melin, J., Peuhkurinen, K., et al. (2007) Prognostic value of cystatin $\mathrm{C}$ in acute heart failure in relation to other markers of renal function and NT-proBNP. European Heart Journal, 28, 1841-1847. doi:10.1093/eurheartj/ehl507

[8] Shenkman, H.J., Zareba, W. and Bisognano, J.D. (2007) Comparison of prognostic significance of amino-terminal pro-brain natriuretic peptide versus blood urea nitrogen for predicting events in patients hospitalized for heart failure. American Journal of Cardiology, 99, 1143-1145. doi:10.1016/j.amjcard.2006.11.050

[9] Filippatos, G., Rossi, J., Lloyd-Jones, D.M., Stough, W.G., Ouyang, J., Shin, D.D., et al. (2007) Prognostic value of blood urea nitrogen in patients hospitalized with worsening heart failure: Insights from the acute and chronic therapeutic impact of a vasopressin antagonist in chronic heart failure (ACTIV in CHF) study. Journal of Cardiac Failure, 13, 360-364. doi:10.1016/j.cardfail.2007.02.005

[10] Valente, M.A., Damman, K., Dunselman, P.H., Hillege, H.L. and Voors, A.A. (2012) Urinary proteins in heart failure. Progress in Cardiovascular Diseases, 55, 44-55. doi:10.1016/j.pcad.2012.04.009

[11] Campbell, C.Y., Clarke, W., Park, H., Haq, N., Barone, B.B. and Brotman, D.J. (2009) Usefulness of cystatin C and prognosis following admission for acute heart failure. American Journal of Cardiology, 104, 389-392. doi:10.1016/j.amjcard.2009.03.059

[12] Damman, K., Van Veldhuisen, D.J., Navis, G., Vaidya, V.S., Smilde, T.D., Westenbrink, B.D., et al. (2010) Tubular damage in chronic systolic heart failure is associated with reduced survival independent of glomerular filtration rate. Heart, 96, 1297-1302. doi:10.1136/hrt.2010.194878

[13] Ronco, C., Cicoira, M. and McCullough, P.A. (2012) Cardiorenal syndrome type 1: Pathophysiological crosstalk leading to combined heart and kidney dysfunction in the setting of acutely decompensated heart failure. American College of Cardiology Foundation, 60, 1031-1042. doi:10.1016/j.jacc.2012.01.077

[14] Damman, K., Navis, G., Voors, A.A., Asselbergs, F.W., Smilde, T.D., Cleland, J.G., et al. (2007) Worsening renal function and prognosis in heart failure: Systematic review 
and meta-analysis. Journal of Cardiac Failure, 13, 599608. doi:10.1016/j.cardfail.2007.04.008

[15] Felker, G.M. and Mentz, R.J. (2012) Diuretics and ultrafiltration in acute decompensated heart failure. Journal of the American College of Cardiology, 59, 2145-2153. doi:10.1016/j.jacc.2011.10.910

[16] Voors, A.A., Dittrich, H.C., Massie, B.M., DeLucca, P., Mansoor, G.A., Metra, M., et al. (2011) Effects of the adenosine A1 receptor antagonist rolofylline on renal function in patients with acute heart failure and renal dysfunction: Results from PROTECT (placebo-controlled randomized study of the selective adenosine A1 receptor antagonist rolofylline for patients hospitalized with acute decompensated heart failure and volume overload to assess treatment effect on congestion and renal function). Journal of the American College of Cardiology, 57, 18991907. doi:10.1016/j.jacc.2010.11.057

[17] Metra, M., Nodari, S., Parrinello, G., Bordonali, T., Bugatti, S., Danesi, R., et al. (2008) Worsening renal function in patients hospitalised for acute heart failure: Clinical implications and prognostic significance. European Journal of Heart Failure, 10, 188-195. doi:10.1016/j.ejheart.2008.01.011

[18] Ronco, C., McCullough, P.A., Anker, S.D., Anand, I., Aspromonte, N., Bagshaw, S.M., et al. (2010) Cardiorenal syndromes: An executive summary from the consensus conference of the acute dialysis quality initiative (ADQI). Contributions to Nephrology, 165, 54-67. doi:10.1159/000313745

[19] Damman, K., Voors, A.A., Hillege, H.L., Navis, G., Lechat, P., van Veldhuisen, D.J., et al. (2010) Congestion in chronic systolic heart failure is related to renal dysfunction and increased mortality. European Journal of Heart Failure, 12, 974-982. doi:10.1093/eurjhf/hfq118

[20] Damman, K., van Deursen, V.M., Navis, G., Voors, A.A., van Veldhuisen, D.J. and Hillege, H.L. (2009) Increased central venous pressure is associated with impaired renal function and mortality in a broad spectrum of patients with cardiovascular disease. Journal of the American College of Cardiology, 53, 582-588. doi:10.1016/j.jacc.2008.08.080

[21] Damman, K., Navis, G., Smilde, T.D., Voors, A.A., van der Bij, W., van Veldhuisen, D.J., et al. (2007) Decreased cardiac output, venous congestion and the association with renal impairment in patients with cardiac dysfunction. European Journal of Heart Failure, 9, 872-878. doi:10.1016/j.ejheart.2007.05.010

[22] Mullens, W., Abrahams, Z., Skouri, H.N., Francis, G.S., Taylor, D.O., Starling, R.C., et al. (2008) Elevated intra-abdominal pressure in acute decompensated heart failure: A potential contributor to worsening renal function? Journal of the American College of Cardiology, 51, 300-306. doi:10.1016/j.jacc.2007.09.043

[23] Damman, K., Voors, A.A., Navis, G., van Veldhuisen, D.J. and Hillege, H.L. (2011) The cardiorenal syndrome in heart failure. Progress in Cardiovascular Diseases, 54, 144-153. doi:10.1016/j.pcad.2011.01.003

[24] Weatherley, B.D., Cotter, G., Dittrich, H.C., DeLucca, P., Mansoor, G.A., Bloomfield, D.M., et al. (2010) Design and rationale of the PROTECT study: A placebo-controlled randomized study of the selective A1 adenosine receptor antagonist rolofylline for patients hospitalized with acute decompensated heart failure and volume overload to assess treatment effect on congestion and renal function. Journal of Cardiac Failure, 16, 25-35. doi:10.1016/j.cardfail.2009.10.025

[25] Elkayam, U., Bitar, F., Akhter, M.W., Khan, S., Patrus, S. and Derakhshani, M. (2004) Intravenous nitroglycerin in the treatment of decompensated heart failure: Potential benefits and limitations. Journal of Cardiovascular Pharmacology and Therapeutics, 9, 227-241. doi:10.1177/107424840400900403

[26] Cotter, G., Metzkor, E., Kaluski, E., Faigenberg, Z., Miller, R., Simovitz, A., et al. (1998) Randomised trial of high-dose isosorbide dinitrate plus low-dose furosemide versus high-dose furosemide plus low-dose isosorbide dinitrate in severe pulmonary oedema. Lancet, 351, 389-393. doi:10.1016/S0140-6736(97)08417-1

[27] Sharon, A., Shpirer, I., Kaluski, E., Moshkovitz, Y., Milovanov, O., Polak, R., et al. (2000) High-dose intravenous isosorbide-dinitrate is safer and better than biPAP ventilation combined with conventional treatment for severe pulmonary edema. Journal of the American College of Cardiology, 36, 832-937. doi:10.1016/S0735-1097(00)00785-3

[28] Mullens, W., Abrahams, Z., Francis, G.S., Skouri, H.N., Starling, R.C., Young, J.B., et al. (2008) Sodium nitroprusside for advanced low-output heart failure. Journal of the American College of Cardiology, 52, 200-207. doi:10.1016/j.jacc.2008.02.083

[29] Bayram, M., De Luca, L., Massie, M.B. and Gheorghiade, M. (2005) Reassessment of dobutamine, dopamine, and milrinone in the management of acute heart failure syndromes. American Journal of Cardiology, 96, 47G-58G. doi:10.1016/j.amjcard.2005.07.021

[30] Packer, M., Carver, J.R., Rodeheffer, R.J., Ivanhoe, R.J., DiBianco, R., Zeldis, S.M., et al. (1991) Effect of oral milrinone on mortality in severe chronic heart failure. The PROMISE study research group. The New England Journal of Medicine, 325, 1468-1475. doi:10.1056/NEJM199111213252103

[31] Stroshane, R.M., Koss, R.F., Biddlecome, C.E., Luczkowec, C. and Edelson, J. (1984) Oral and intravenous pharmacokinetics of milrinone in human volunteers. Journal of Pharmaceutical Sciences, 73, 1438-1441. doi:10.1002/jps.2600731029

[32] Klein, L., Massie, B.M., Leimberger, J.D., O’Connor, C.M., Pina, I.L., Adams Jr., K.F., et al. (2008) Admission or changes in renal function during hospitalization for worsening heart failure predict postdischarge survival: Results from the outcomes of a prospective trial of intravenous milrinone for exacerbations of chronic heart failure (OPTIME-CHF). Circulation: Heart Failure, 1, 25-33. doi:10.1161/CIRCHEARTFAILURE.107.746933

[33] Wei, C.M., Lerman, A., Rodeheffer, R.J., McGregor, C.G., Brandt, R.R., Wright, S., et al. (1994) Endothelin in human congestive heart failure. Circulation, 89, 15801586. doi:10.1161/01.CIR.89.4.1580 
[34] Modesti, P.A., Cecioni, I., Costoli, A., Poggesi, L., Galanti, G. and Serneri, G.G. (2000) Renal endothelin in heart failure and its relation to sodium excretion. American Heart Journal, 140, 617-622. doi:10.1067/mhj.2000.109917

[35] Kaluski, E., Kobrin, I., Zimlichman, R., Marmor, A., Krakov, O., Milo, O., et al. (2003) RITZ-5: Randomized intravenous TeZosentan (an endothelin-A/B antagonist) for the treatment of pulmonary edema: A prospective, multicenter, double-blind, placebo-controlled study. Journal of the American College of Cardiology, 41, 204-210. doi:10.1016/S0735-1097(02)02708-0

[36] Torre-Amione, G., Young, J.B., Colucci, W.S., Lewis, B.S., Pratt, C., Cotter, G., et al. (2003) Hemodynamic and clinical effects of tezosentan, an intravenous dual endothelin receptor antagonist, in patients hospitalized for acute decompensated heart failure. Journal of the American College of Cardiology, 42, 140-147. doi:10.1016/S0735-1097(03)00556-4

[37] Teerlink, J.R., McMurray, J.J., Bourge, R.C., Cleland, J.G., Cotter, G., Jondeau, G., et al. (2005) Tezosentan in patients with acute heart failure: Design of the value of endothelin receptor inhibition with tezosentan in acute heart failure study (VERITAS). American Heart Journal, 150, 46-53. doi:10.1016/j.ahj.2005.04.035

[38] Neuhofer, W. and Pittrow, D. (2006) Role of endothelin and endothelin receptor antagonists in renal disease. European Journal of Clinical Investigation, 36, 78-88. doi:10.1111/j.1365-2362.2006.01689.x

[39] Colucci, W.S., Elkayam, U., Horton, D.P., Abraham, W.T., Bourge, R.C., Johnson, A.D., et al. (2000) Intravenous nesiritide, a natriuretic peptide, in the treatment of decompensated congestive heart failure. Nesiritide study group. The New England Journal of Medicine, 343, 246253. doi:10.1056/NEJM200007273430403

[40] Mills, R.M., LeJemtel, T.H., Horton, D.P., Liang, C., Lang, R., Silver, M.A., et al. (1999) Sustained hemodynamic effects of an infusion of nesiritide (human b-type natriuretic peptide) in heart failure: A randomized, double-blind, placebo-controlled clinical trial. Natrecor study group. Journal of the American College of Cardio- logy, 34, 155-162. doi:10.1016/S0735-1097(99)00184-9

[41] Mitrovic, V., Seferovic, P.M., Simeunovic, D., Ristic, A.D., Miric, M., Moiseyev, V.S., et al. (2006) Haemodynamic and clinical effects of ularitide in decompensated heart failure. European Heart Journal, 27, 28232832. doi:10.1093/eurheartj/ehl337

[42] McKie, P.M., Sangaralingham, S.J. and Burnett Jr., J.C. (2010) CD-NP: An innovative designer natriuretic peptide activator of particulate guanylyl cyclase receptors for cardiorenal disease. Current Heart Failure Reports, 7,93-99. doi:10.1007/s11897-010-0016-6

[43] Mitrovic, V., Hernandez, A.F., Meyer, M. and Gheorghiade, M. (2009) Role of guanylate cyclase modulators in decompensated heart failure. Heart Failure Reviews, 14, 309-319. doi:10.1007/s10741-009-9149-7

[44] Sackner-Bernstein, J.D., Skopicki, H.A. and Aaronson, K.D. (2005) Risk of worsening renal function with nesiritide in patients with acutely decompensated heart failure.
Circulation, 111, 1487-1491. doi:10.1161/01.CIR.0000159340.93220.E4

[45] Sackner-Bernstein, J.D., Kowalski, M., Fox, M. And Aaronson, K. (2005) Short-term risk of death after treatment with nesiritide for decompensated heart failure: A pooled analysis of randomized controlled trials. JAMA, 293, 1900-1905. doi:10.1001/jama.293.15.1900

[46] Arora, R.R., Venkatesh, P.K. and Molnar, J. (2006) Short and long-term mortality with nesiritide. American Heart Journal, 152, 1084-1090. doi:10.1016/j.ahj.2006.07.002

[47] O’Connor, C.M., Starling, R.C., Hernandez, A.F., Armstrong, P.W., Dickstein, K., Hasselblad, V., et al. (2011) Effect of nesiritide in patients with acute decompensated heart failure. The New England Journal of Medicine, 365, 32-43. doi:10.1056/NEJMoa1100171

[48] Mitrovic, V., Luss, H., Nitsche, K., Forssmann, K., Maronde, E., Fricke, K., et al. (2005) Effects of the renal natriuretic peptide urodilatin (ularitide) in patients with decompensated chronic heart failure: A double-blind, placebo-controlled, ascending-dose trial. American Heart Journal, 150, 1239. doi:10.1016/j.ahj.2005.01.022

[49] Luss, H., Mitrovic, V., Seferovic, P.M., Simeunovic, D., Ristic, A.D., Moiseyev, V.S., et al. (2008) Renal effects of ularitide in patients with decompensated heart failure. American Heart Journal, 155, 1012.e1-1012.e8.

[50] Martin, F.L., Sangaralingham, S.J., Huntley, B.K., McKie, P.M., Ichiki, T., Chen, H.H., et al. (2012) CD-NP: A novel engineered dual guanylyl cyclase activator with anti-fibrotic actions in the heart. PLoS One, 7, e52422. doi:10.1371/journal.pone.0052422

[51] Rose, R.A. (2010) CD-NP, a chimeric natriuretic peptide for the treatment of heart failure. Current Opinion in Investigational Drugs, 11, 349-356.

[52] Lee, C.Y., Chen, H.H., Lisy, O., Swan, S., Cannon, C., Lieu, H.D., et al. (2009) Pharmacodynamics of a novel designer natriuretic peptide, CD-NP, in a first-in-human clinical trial in healthy subjects. The Journal of Clinical Pharmacology, 49, 668-673. doi:10.1177/0091270009336233

[53] Fischer, D., Rossa, S., Landmesser, U., Spiekermann, S., Engberding, N., Hornig, B., et al. (2005) Endothelial dysfunction in patients with chronic heart failure is independently associated with increased incidence of hospitalization, cardiac transplantation, or death. European Heart Journal, 26, 65-69. doi:10.1093/eurheartj/ehi001

[54] Surmeli, N. and Marletta, M.A. (2012) Insight into the rescue of oxidized soluble guanylate cyclase by the activator cinaciguat. ChemBioChem, 13, 977-981. doi:10.1002/cbic.201100809

[55] Erdmann, E., Semigran, M.J., Nieminen, M.S., Gheorghiade, M., Agrawal, R., Mitrovic, V., et al. (2013) Cinaciguat, a soluble guanylate cyclase activator, unloads the heart but also causes hypotension in acute decompensated heart failure. European Heart Journal, 34, 57-67. doi:10.1093/eurheartj/ehs196

[56] Lapp, H., Mitrovic, V., Franz, N., Heuer, H., Buerke, M., Wolfertz, J., et al. (2009) Cinaciguat (BAY 58-2667) improves cardiopulmonary hemodynamics in patients with 
acute decompensated heart failure. Circulation, 119, 2781-1788.

doi:10.1161/CIRCULATIONAHA.108.800292

[57] Gheorghiade, M., Greene, S.J., Filippatos, G., Erdmann, E., Ferrari, R., Levy, P.D., et al. (2012) Cinaciguat, a soluble guanylate cyclase activator: Results from the randomized, controlled, phase IIb COMPOSE programmme in acute heart failure syndromes. European Journal of Heart Failure, 14, 1056-1066. doi:10.1093/eurjhf/hfs093

[58] Oghlakian, G. and Klapholz, M. (2009) Vasopressin and vasopressin receptor antagonists in heart failure. Cardiology in Review, 17, 10-15.

doi:10.1097/CRD.0b013e318190e72c

[59] Gheorghiade, M., Gattis, W.A., O’Connor, C.M., Adams Jr., K.F., Elkayam, U., Barbagelata, A., et al. (2004) Effects of tolvaptan, a vasopressin antagonist, in patients hospitalized with worsening heart failure: A randomized controlled trial. JAMA, 291, 1963-1971. doi:10.1001/jama.291.16.1963

[60] Gheorghiade, M., Gattis, W.A., Barbagelata, A., Adams Jr., KF, Elkayam, U., Orlandi, C., et al. (2003) Rationale and study design for a multicenter, randomized, doubleblind, placebo-controlled study of the effects of tolvaptan on the acute and chronic outcomes of patients hospitalized with worsening congestive heart failure. American Heart Journal, 145, S51-S54. doi:10.1067/mhj.2003.154

[61] Gheorghiade, M., Niazi, I., Ouyang, J., Czerwiec, F., Kambayashi, J., Zampino, M., et al. (2003) Vasopressin V2-receptor blockade with tolvaptan in patients with chronic heart failure: Results from a double-blind, randomized trial. Circulation, 107, 2690-2696. doi:10.1161/01.CIR.0000070422.41439.04

[62] Konstam, M.A., Gheorghiade, M., Burnett Jr., J.C., Grinfeld, L., Maggioni, A.P., Swedberg, K., et al. (2007) Effects of oral tolvaptan in patients hospitalized for worsening heart failure: The EVEREST outcome trial. JAMA, 297, 1319-1331. doi:10.1001/jama.297.12.1319

[63] Gheorghiade, M., Konstam, M.A., Burnett Jr., J.C., Grinfeld, L., Maggioni, A.P., Swedberg, K., et al. (2007) Short-term clinical effects of tolvaptan, an oral vasopressin antagonist, in patients hospitalized for heart failure: The EVEREST clinical status trials. JAMA, 297, 1332-1343. doi:10.1001/jama.297.12.1332

[64] Udelson, J.E., Smith, W.B., Hendrix, G.H., Painchaud, C.A., Ghazzi, M., Thomas, I., et al. (2001) Acute hemodynamic effects of conivaptan, a dual V(1A) and V(2) vasopressin receptor antagonist, in patients with advanced heart failure. Circulation, 104, 2417-2423. doi:10.1161/hc4501.099313

[65] Burnier, M., Fricker, A.F., Hayoz, D., Nussberger, J. and Brunner, H.R. (1999) Pharmacokinetic and pharma- codynamic effects of YM087, a combined V1/V2 vasopressin receptor antagonist in normal subjects. European Journal of Clinical Pharmacology, 55, 633-637. doi:10.1007/s002280050685

[66] Mondritzki, T., Kolkhof, P., Sabbah, H.N., Gheorghiade, M., Furstner, C., Schmeck, C., et al. (2011) Differentia- tion of arginine vasopressin antagonistic effects by selective V2 versus dual V2/V1a receptor blockade in a preclinical heart failure model. American Journal of Therapeutics, 18, 31-37. doi:10.1097/MJT.0b013e3181f890ad

[67] Goldsmith, S.R. (2012) Hyponatremia and outcomes in patients with heart failure. Heart, 98, 1761-1762. doi:10.1136/heartjnl-2012-302854

[68] Givertz, M.M., Massie, B.M., Fields, T.K., Pearson, L.L. and Dittrich H,C. (2007) CKI-201 and CKI-202 Investigators. The effects of KW-3902, an adenosine A1-receptor antagonist, on diuresis and renal function in patients with acute decompensated heart failure and renal impairment or diuretic resistance. Journal of the American College of Cardiology, 50, 1551-1560. doi:10.1016/j.jacc.2007.07.019

[69] Gottlieb, S.S., Brater, D.C., Thomas, I., Havranek, E., Bourge, R., Goldman, S., et al. (2002) BG9719 (CVT124), an A1 adenosine receptor antagonist, protects against the decline in renal function observed with diuretic therapy. Circulation, 105, 1348-1353. doi:10.1161/hc1102.105264

[70] Massie, B.M., O’Connor, C.M., Metra, M., Ponikowski, P., Teerlink, J.R., Cotter, G., et al. (2010) Rolofylline, an adenosine A1-receptor antagonist, in acute heart failure. The New England Journal of Medicine, 363, 1419-1428. doi:10.1056/NEJMoa0912613

[71] Gottlieb, S.S., Ticho, B., Deykin, A., Abraham, W.T., Denofrio, D., Russell, S.D., et al. (2011) Effects of BG9928, an adenosine A(1) receptor antagonist, in patients with congestive heart failure. The Journal of Clinical Pharmacology, 51, 899-907. doi:10.1177/0091270010375957

[72] Greenberg, B., Thomas, I., Banish, D., Goldman, S., Havranek, E., Massie, B.M., et al. (2007) Effects of multiple oral doses of an A1 adenosine antagonist, BG9928, in patients with heart failure: Results of a placebo-controlled, dose-escalation study. Journal of the American College of Cardiology, 50, 600-606. doi:10.1016/j.jacc.2007.03.059

[73] Sorsa, T., Heikkinen, S., Abbott, M.B., Abusamhadneh, E., Laakso, T., Tilgmann, C., et al. (2001) Binding of levosimendan, a calcium sensitizer, to cardiac troponin C. Journal of Biological Chemistry, 276, 9337-9343. doi:10.1074/jbc.M007484200

[74] Janssen, P.M., Datz, N., Zeitz, O. and Hasenfuss, G. (2000) Levosimendan improves diastolic and systolic function in failing human myocardium. European Journal of Pharmacology, 404, 191-199. doi:10.1016/S0014-2999(00)00609-9

[75] Hasenfuss, G., Pieske, B., Castell, M., Kretschmann, B., Maier, L.S. and Just. H. (1998) Influence of the novel inotropic agent levosimendan on isometric tension and calcium cycling in failing human myocardium. Circulation, 98, 2141-2147. doi:10.1161/01.CIR.98.20.2141

[76] Krassoi, I., Pataricza, J., Kun, A. and Papp, J.G. (2000) Calcium-dependent vasorelaxant capacity of levosimendan in porcine and human epicardial coronary artery preparations. Cardiovascular Drugs and Therapy, 14, 691-693. doi:10.1023/A:1007883402379 
[77] Pataricza, J., Hohn, J., Petri, A., Balogh, A. and Papp, J.G. (2000) Comparison of the vasorelaxing effect of cromakalim and the new inodilator, levosimendan, in human isolated portal vein. Pharmaceutical \& Medicinal Chemistry, 52, 213-217. doi:10.1211/0022357001773715

[78] Packer, M. (2005) REVIVE-II: Multicenter placebocontrolled trial of levosimendan on clinical status in acutely decompensated heart failure. Circulation, 112, 3362-3364.

[79] Mebazaa, A., Nieminen, M.S., Packer, M., Cohen-Solal, A., Kleber, F.X., Pocock, S.J., et al. (2007) Levosimendan vs dobutamine for patients with acute decompensated heart failure: The SURVIVE randomized trial. JAMA, 297, 1883-1891. doi:10.1001/jama.297.17.1883

[80] Moiseyev, V.S., Poder, P., Andrejevs, N., Ruda, M.Y., Golikov, A.P., Lazebnik, L.B., et al. (2002) Safety and efficacy of a novel calcium sensitizer, levosimendan, in patients with left ventricular failure due to an acute myocardial infarction. A randomized, placebo-controlled, double-blind study (RUSSLAN). European Heart Journal, 23, 1422-1432. doi:10.1053/euhj.2001.3158

[81] Follath, F., Cleland, J.G., Just, H., Papp, J.G., Scholz, H., Peuhkurinen, K., et al. (2002) Efficacy and safety of intravenous levosimendan compared with dobutamine in severe low-output heart failure (the LIDO study): A randomised double-blind trial. Lancet, 360, 196-202. doi:10.1016/S0140-6736(02)09455-2

[82] Yilmaz, M.B., Yalta, K., Yontar, C., Karadas, F., Erdem, A., Turgut, O.O., et al. (2007) Levosimendan improves renal function in patients with acute decompensated heart failure: Comparison with dobutamine. Cardiovascular Drugs and Therapy, 21, 431-435. doi:10.1007/s10557-007-6066-7

[83] Zemljic, G., Bunc, M., Yazdanbakhsh, A.P. and Vrtovec, B. (2007) Levosimendan improves renal function in patients with advanced chronic heart failure awaiting cardiac transplantation. Journal of Cardiac Failure, 13, 417-421. doi:10.1016/j.cardfail.2007.03.005

[84] Hou, Z.Q., Sun, Z.X., Su, C.Y., Tan, H., Zhong, X., Hu, B., et al. (2012) Effect of levosimendan on estimated glomerular filtration rate in hospitalized patients with decompensated heart failure and renal dysfunction. Car- diovascular Therapeutics, Accepted article. doi:10.1111/cdr.12001

[85] Parissis, J.T., Farmakis, D. and Nieminen, M. (2007) Classical inotropes and new cardiac enhancers. Heart Fail Reviews, 12, 149-156. doi:10.1007/s10741-007-9014-5

[86] Teichman, S.L., Unemori, E., Dschietzig, T., Conrad, K., Voors, A.A., Teerlink, J.R., et al. (2009) Relaxin, a pleiotropic vasodilator for the treatment of heart failure. Heart Fail Reviews, 14, 321-329. doi:10.1007/s10741-008-9129-3

[87] Dschietzig, T., Teichman, S., Unemori, E., Wood, S., Boehmer, J., Richter, C., et al. (2009) Intravenous recombinant human relaxin in compensated heart failure: A safety, tolerability, and pharmacodynamic trial. Journal of Cardiac Failure, 15, 182-190. doi:10.1016/j.cardfail.2009.01.008

[88] Teichman, S.L., Unemori, E., Teerlink, J.R., Cotter, G. and Metra, M. (2010) Relaxin: Review of biology and potential role in treating heart failure. Current Heart Failure Reports, 7, 75-82. doi:10.1007/s11897-010-0010-z

[89] Teerlink, J.R., Cotter, G., Davison, B.A., Felker, G.M., Filippatos, G., Greenberg, B.H., et al. (2013) Serelaxin, recombinant human relaxin-2, for treatment of acute heart failure (RELAX-AHF): A randomised, placebo-controlled trial. Lancet, 381, 29-39. doi:10.1016/S0140-6736(12)61855-8

[90] Metra, M., Cotter, G., Davison, B.A., Felker, G.M., Filippatos, G., Greenberg, B.H., et al. (2013) Effect of serelaxin on cardiac, renal, and hepatic biomarkers in the relaxin in acute heart failure (RELAX-AHF) development program: Correlation with outcomes. American College of Cardiology Foundation, 61, 196-206.

[91] Damman, K. and Voors, A.A. (2007) Levosimendan improves renal function in acute decompensated heart failure: Cause and clinical application. editorial to: "Levosimendan improves renal function in patients with acute decompensated heart failure: Comparison with dobutamine by yilmaz et al." Cardiovascular Drugs and Therapy, 21, 403-404. doi:10.1007/s10557-007-6070-y 